\section{Final drive lubrication modeling}

\author{
E.V.Avdeev<j-avdeev@yandex.ru> \\ ${ }^{2}$ K.A. Volkova $<$ volkova_k.a_92@mail.ru> \\ ${ }^{3}$ V.A. Ovchinnikov<vovchinnikov@laduga.com> \\ 1Korolev Samara National Research University, 443086, Russia, Samara \\ Moskovskoe Shosse 34A \\ ${ }^{2}$ Peter the Great St.Petersburg Polytechnic University, 195251, Russia, \\ St.Petersburg, Polytehnicheskaia 29 \\ ${ }^{3}$ Laduga Automotive Engineering, 445037, Russia, Togliatti, Frunze 14B
}

Abstract. In this paper, we describe the method, which is the composition of finite volume method (FVM) and adaptive mesh refinement (AMR). We use it to solve car final drive inner volume oil lubrication problem. The computational algorithm is implemented using OpenFOAM parallel library that provides data structures and routines to work with the finite volume method and adaptive mesh. This library supports parallelism through OpenMPI. The paper presents the results of numerical simulation.

Keywords: lubrication modeling, adaptive mesh refinement, final drive modeling, bearing modeling.

DOI: $10.15514 /$ ISPRAS-2017-29(6)-21

For citation: Avdeev E.V., Volkova K. A., Ovchinnikov V.A. Final drive lubrication modeling. Trudy ISP RAN/Proc. ISP RAS, vol. 29, issue 6, 2017. pp. 321-330. DOI: 10.15514/ISPRAS 2017-29(6)-21

\section{Introduction}

In recent years, automotive industry becomes increasingly competitive and global in nature. This forces the car manufacturers to optimize components and assemblies, in order to reduce the cost of their production, but without performance reducing.

This paper considers a design of automobile final drive. Final drive design is based on the fulfillment of the technical requirements and carried out by conducting separated modeling cases: stress analysis, kinematic analysis, thermal analysis, manufacturability analysis, oil flow analysis. So one of the problems arising during the final drive design is related to the oil lubricity analysis. In particular, the authors of this paper solved the problem of the oil flow simulation created by rotating gear wheel of final drive. The calculation results are transferred to design engineer, who will update the shape of the final drive body accordingly to technical requirements
In particular, oil flow has to reach the stuffing box (see Fig. 1) and this flow has to be ufficient.

\section{Problem Formulation}

The final drive inner volume oil lubricity problem is to simulate oil distribution under the gear wheel, shaft and bearings rotation. After the technical requirements analysis we decide to perform lubrication modeling for the following shaft rotationa frequencies: 551, 800, 1600, $2400 \mathrm{rev} / \mathrm{min}$. This rotational frequencies set describes final drive basic operating modes.

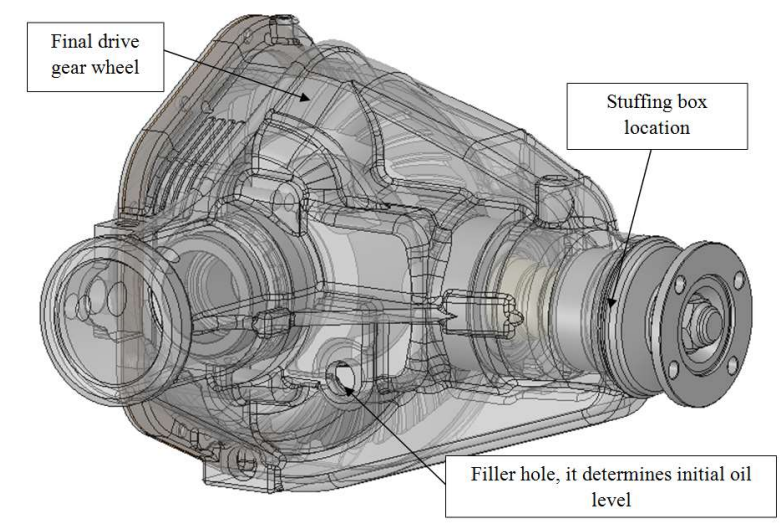

Fig. 1. The original geometry and the basic elements of the final drive

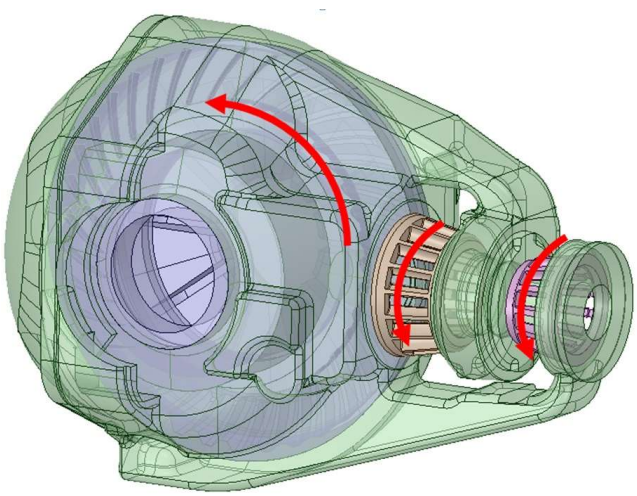

Fig. 2. The final drive internal volume, gear wheel and bearings rotation directions 
To simulate lubricity we decided to use a two-phase liquid-air model without taking into account the compressibility, heat transfer and miscibility. For phase separation we use VOF method, such as Lemfeld [1], Chunfeng [2]. For more efficient use of computing resources, we decided to use an approach based on the use of adaptive mesh refinement/coarsening (Adaptive Mesh Refinement - AMR). AMR procedure implemented in the OpenFOAM library [3]. Wherein the original OpenFOAM library does not support AMR usage simultaneously with the rotating mesh domains. So it was necessary to conduct OpenFOAM library modifications.

\section{Adaptation method}

There is a large amount of literature, which deals with dynamic mesh and mesh adaptation methods. One of the first works on dynamic mesh application were investigations of Miller [4] and Yanenko [5]. Currently, the mesh adaptation technologies are widely used in numerical problems solving. Mesh adaptation methods usually based on minimization of some selected functional. It is achieved by refinement or coarsening of mesh elements (h-adaptation) or mesh nodes moving (padaptation).

Adaptive mesh allow to reduce computational cost, to correct mesh in complex areas, to handle moving surfaces, phase transitions and other areas of high gradients. Mesh adaptation approaches was successfully implemented by developers of commercial and non-commercial software packages such as FlowVision, Abaqus, Ansys, OpenFOAM. In this study, we used an OpenFOAM open library, which has complete modules for AMR implementation.

For AMR configuration in OpenFOAM user need to provide following information:

- mesh update frequency (update mesh on every first, second or subsequent iteration);

- scalar field, whose values will be used for the mesh refinement/coarsening;

- field values interval, defined by minimum and maximum values, at which we want to refine mesh;

- field threshold value, below which we want to start mesh coarsening;

- maximum cells refinement level relative to initial mesh cells;

- the maximum allowable mesh cells amount.

In this work as scalar field we use field, based on discretization matrix eigenvalues estimation. This method described in more detail in our previous work [6].

Current version of OpenFOAM-v1612 does not allow to use mesh adaptation (implemented by dynamicRefineFvMesh class) and rotation of the mesh (implemented by solidBodyMotionFvMesh class) simultaneously. Therefore, to achieve the desired functionality, we have created a new $\mathrm{C}++$ class solidBodyMotion dynamicRefineFvMesh by virtual inheritance. The sources available at [7].

\section{Computational results and analysis}

We consider the mathematical model, which describes oil distribution during final drive gear wheel rotation.

Oil distribution is described by the following equations [8]:

$$
\frac{\partial \alpha_{\varphi} \overline{U_{\varphi}}}{\partial t}+\nabla \mathrm{g}\left(\alpha_{\varphi} \overline{U_{\varphi}} \overline{U_{\varphi}}\right)+\nabla \mathrm{g}\left(\alpha_{\varphi} \bar{R}_{\varphi}^{e f f}\right)=-\frac{\alpha_{\varphi}}{\rho_{\varphi}} \nabla \bar{p}+\alpha_{\varphi} g+\frac{\overline{M_{\varphi}}}{\rho_{\varphi}} \frac{\partial \alpha_{\varphi}}{\partial t}+\nabla \mathrm{g}\left(\overline{U_{\varphi}} \alpha_{\varphi}\right)=0,
$$

where $\varphi$ - phase, $\alpha$-phase fraction, $\bar{R}_{\varphi}^{\text {eff }}$ is combined Reynolds (turbulent) and viscous stress, $\overline{M_{\varphi}}$ - averaged inter-phase momentum transfer term, $\overline{U_{\varphi}}$ - averaged transport velocity, $p$ - pressure, $t$ - time discretization step size, $g$ - acceleration due to gravity, $\rho_{\varphi}-$ phase density.

Combining equation (1) for two phases with $\varphi=a$ and $b$ yields the volumetric continuity equation for the mixture, which will be utilized to formulate an implicit equation for the pressure. The volumetric continuity equation reads:

$$
\nabla \mathrm{g} \bar{U}=0
$$

where $\bar{U}=\alpha_{\alpha} \overline{U_{\alpha}}+\alpha_{\alpha} \overline{U_{b}}$.

The averaged equations representing the conservation of mass and momentum for each phase.

Fig. 3 shows the oil-air free surface for wheel rotational frequency $551 \mathrm{rev} / \mathrm{min}$, time $=1.7 \mathrm{~s}$ 


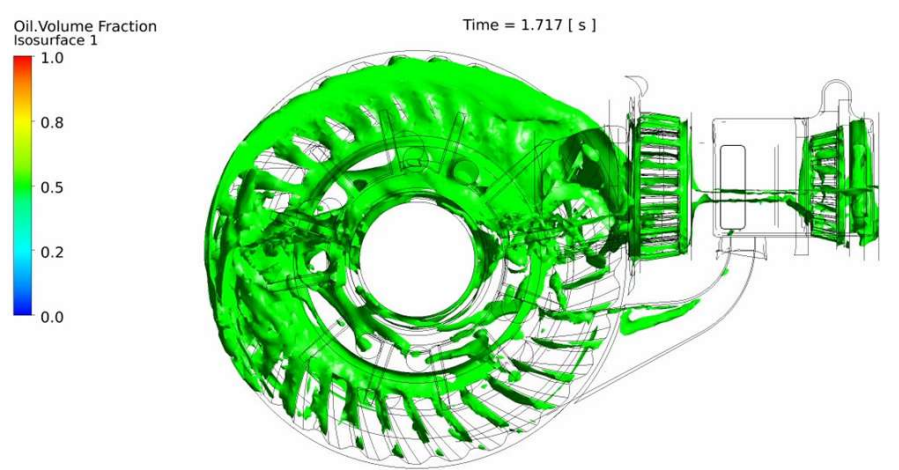

Fig. 3. Oil-air free surface for wheel rotational frequency $551 \mathrm{rev} / \mathrm{min}$, time $t=1.7 \mathrm{~s}$.

Fig, 4 shows the oil distribution for wheel rotational frequency $551 \mathrm{rev} / \mathrm{min}$, time $\mathrm{t}=$ $1.7 \mathrm{~s}$. It can be seen that in this case the oil flow reaches the stuffing box location.

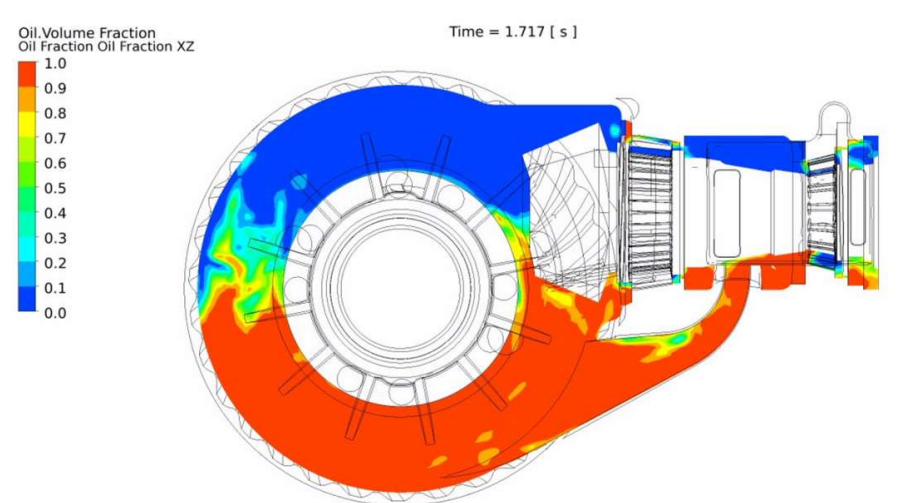

Fig. 4. Oil distribution for wheel rotational frequency $551 \mathrm{rev} / \mathrm{min}$, time $t=1.7 \mathrm{~s}$.

Fig. 5 and fig. 6 show the oil distribution for wheel rotational frequency $2400 \mathrm{rev} / \mathrm{min}$, time $\mathrm{t}=0.149 \mathrm{~s}$. It can be seen that in this case the oil flow behavior is more stochastic.

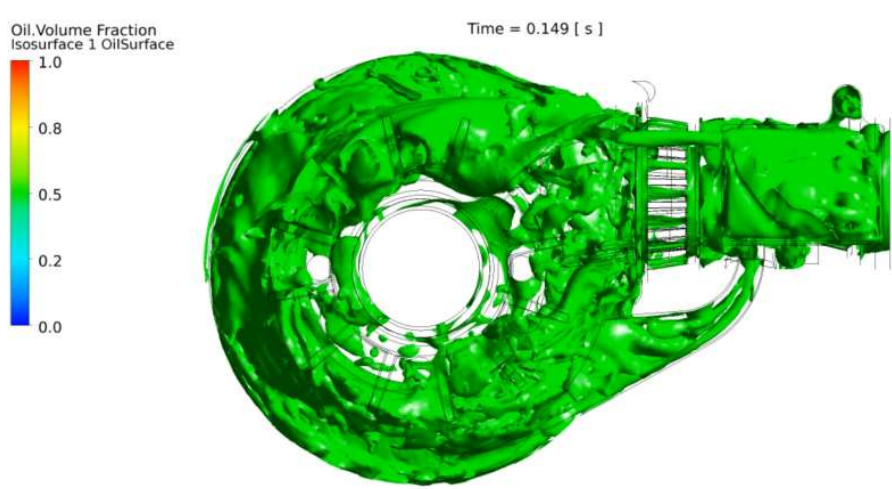

Fig. 5. Oil-air free surface for wheel rotational frequency $2400 \mathrm{rev} / \mathrm{min}$, time $t=0.149 \mathrm{~s}$.

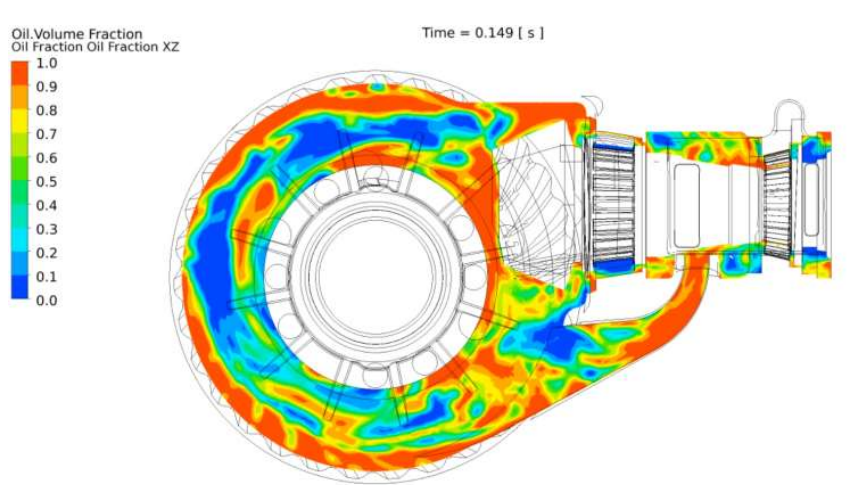

Fig. 6. Oil distribution for wheel rotational frequency $2400 \mathrm{rev} / \mathrm{min}$, time $t=0.149 \mathrm{~s}$

Adaptive mesh refinement more effective in areas of constant oil flow form, less effective in areas with stochastic oil flow behavior. 


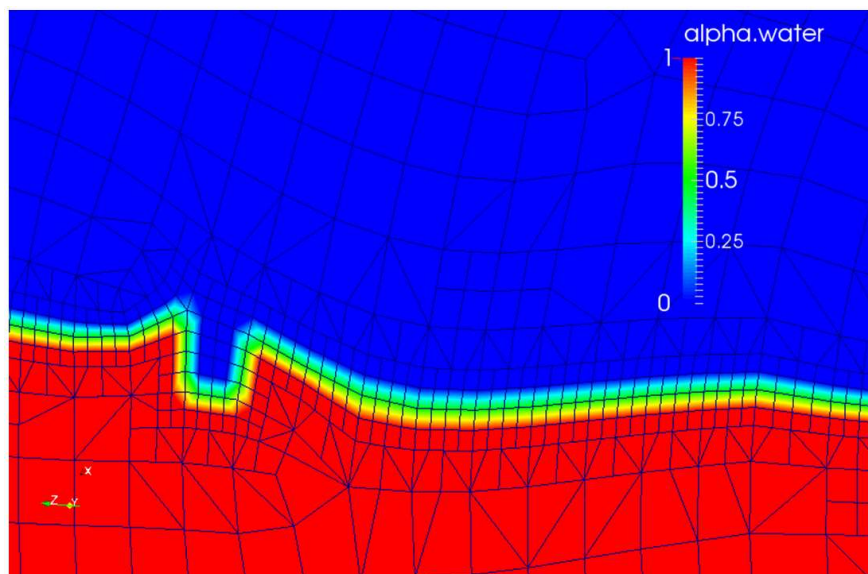

Fig. 7. Mesh fragment, wheel rotational frequency $551 \mathrm{rev} / \mathrm{min}$, time $t=1 \mathrm{e}-6 \mathrm{~s}$.

Fig. 7 shows mesh fragment for case of wheel rotational frequency $551 \mathrm{rev} / \mathrm{min}$, time $\mathrm{t}=1 \mathrm{e}-6 \mathrm{~s}$. More fine mesh formed in areas with a higher phase fraction gradient, which reduces task computational cost.

\section{Computational results and analysis}

Algorithms parallelization performed by built-in features of OpenFOAM paralle library. The method of parallel computing used in OpenFOAM is based on the computational domain mesh and fields decomposition into separate parts, every single part is assigned to a separate computing core. Thus, the parallel calculation process includes the following steps: mesh and fields decomposition; parallel solver run; postprocessing after mesh and fields reconstruction or right in the decomposed form. OpenFOAM supports OpenMPI implementation of the standard message passing interface MPI by default, it is also possible to connect other MPI implementation libraries. We consider the mathematical model, which describes oil distribution during final drive gear wheel rotation.

All computations are performed on cluster "Sergey Korolev". In particular, we used two server types:

- HS22 blade servers, each of them has 2x CPU: Intel Xeon X5560, 4 cores;

- HS23 blade servers, each of them has 2x CPU: Intel Xeon E5-2665, 8 cores.

Execution time comparison for this server types showed on Fig. 8

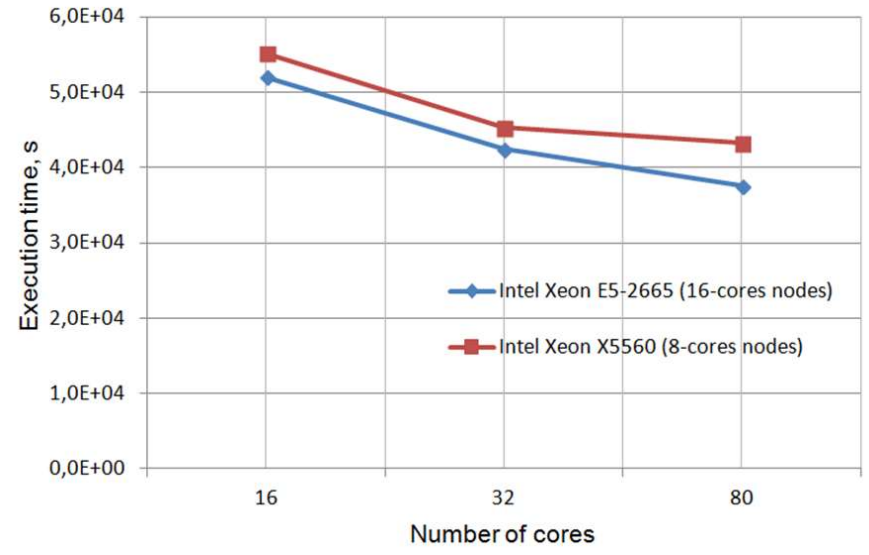

Fig. 8. Execution time for different number of cores and nodes types.

\section{Conclusion}

An implemented by OpenFOAM library model has shown efficiency and stability. Adaptive mesh refinement along with the ability to use parallel computing also provides computational costs reduction compared to the static mesh.

Adaptive mesh refinement adaptation showed its greater effectiveness in areas of constant oil flow form, accordingly less effectiveness in areas with stochastic oil flow behavior. Thus adaptive mesh refinement showed its greater effectiveness in the case of a lower frequency (551 rev/min and $800 \mathrm{rev} / \mathrm{min}$ ). After the simulation results analysis final drive designer made a decision to add a plastic plate, which will correct the oil flow inside the final drive. At the time of this writing, experiments have not yet been conducted. This work will be continued after experimental results analysis.

\section{References}

[1]. F. Lemfeld, K. Fran, J. Unger. Numerical simulations of unsteady oil flows in the gearboxes. Journal of applied science in the thermodynamics and fluid mechanics -vol. 1 , 2007, pp. 1-5.

2]. V. Vande, J. Vierendeels, E. Dick. Flow simulations in rotary volumetric pumps an compressors with the fictious domain method. Journal of Computational and Applied Mathematics, vol.168 (1-2), 2004, pp. 491-499.

[3]. OpenFOAM UserGuide [Electronic resource]. - Access mode: http://foam.sourceforge.net/docs/Guides-a4/OpenFOAMUserGuide-A4.pdf (4.02.2017).

[4]. K. Miller, R.N. Miller. Moving finite elements. Journal on Numerical Analysis, SIAM, vol. 18(6), 1981, pp. 1019-1032

[5]. N.N. Yanenko, V.D. Lisseikin, V.M. Kovenia. The method of the solution of gaz dynamical problems in moving meshes. Computing Methods in Applied Sciences and Engineering, vol. 91(2), 1977, pp. 48-61. 
[6]. E. Avdeev, V. Fursov, V. Ovchinnikov. An adaptive mesh refinement in the finite volume method. Proceedings of Information Technology and Nanotechnology (ITNT-2015), CEUR Workshop Proceedings, vol. 1490, 2015, pp. 234-241.

7]. Dijkstra E.W. A Discipline of Programming. Prentice-Hall, 1976. 217 p.

[8]. Final drive lubrication OpenFOAM case sources [Electronic resource]. - Access mode: https://github.com/j-avdeev/DriveLubrication (4.02.2017).

[9]. H. Rusche, Computational Fluid Dynamics of Dispersed Two-Phase Flows at High Phase Fractions [Electronic resource]. Access mode:

http://powerlab.fsb.hr/ped/kturbo/OpenFOAM/docs/HenrikRuschePhD2002.pdf (4.02.2017).

\section{Моделирование смазочной системы главной передачи}

${ }^{1}$ E.B. Авдеев $<$-avdeev@yandex.ru>

${ }^{2}$ K.A. Волкова <volkova k.a92@mail.ru>

${ }_{3}^{3}$ B.A. Овчинников <vovchinnikov@laduga.com>

${ }^{1}$ Самарский национальный исследовательский университет имени

$$
\text { С.П. Королева }
$$

443086, Россия, г. Самара, ул. Московское шоссе, д. 34

${ }^{2}$ Санкт-Петербургский политехнический университет Петра Великого

$$
\text { 195251, Россия, г. Санкт-Петербург, Политехническая, } 29
$$

$$
\text { Инжиниринговый цеентр Ладуга }
$$

445037, Самарская обл., г.Тольятти, ул. Фрунзе, д.14-Б

Аннотация. В этой статье мы описываем метод, который представляет собой композицию метода конечных объемов (finite volume method, FVM) и метода адаптивного измельчения расчётной сетки (adaptive mesh refinement, AMR). M используем его для решения проблемы масляной смазки объема внутренней полости главной передачи автомобиля. Вычислительный алгоритм реализован с использованием параллельной библиотеки OpenFOAM, которая предоставляет структуры данных подпрограммы для работы с методами конечных объемов и адаптивной сетки. Эта библиотека поддерживает параллелизм на основе OpenMPI. В статье представлень результаты численного моделирования.

Ключевые слова: моделирование смазки; алаптивное измельчение сетки; моделирование главной передачи; моделирование подшипников

DOI: $10.15514 /$ ISPRAS-2017-29(6)-21

For citation: Авдеев Е.В., Волкова К.А., Овчинников В.А. Моделирование смазочной системы главной передачи. Труды ИСП РАН, том 29, вып. 6, 2017 г., стр. 321-330 (на английском языке). DOI: 10.15514/ISPRAS-2017-29(6)-21

\section{Список литературы}

[1]. F. Lemfeld, K. Fran, J. Unger. Numerical simulations of unsteady oil flows in the gearboxes. Journal of applied science in the thermodynamics and fluid mechanics -vol. 1, 2007, pp. 1-5.

[2]. V. Vande, J. Vierendeels, E. Dick. Flow simulations in rotary volumetric pumps and compressors with the fictious domain method. Journal of Computational and Applied Mathematics, vol.168 (1-2), 2004, pp. 491-499.

[3]. OpenFOAM UserGuide [Электронный pecypc]. — Access mode: http://foam.sourceforge.net/docs/Guides-a4/OpenFOAMUserGuide-A4.pdf (4.02.2017).

[4]. K. Miller, R.N. Miller. Moving finite elements. Journal on Numerical Analysis, SIAM, vol. 18(6), 1981, pp. 1019-1032.

[5]. N.N. Yanenko, V.D. Lisseikin, V.M. Kovenia. The method of the solution of gaz dynamical problems in moving meshes. Computing Methods in Applied Sciences and Engineering, vol. 91(2), 1977, pp. 48-61.

[6]. E. Avdeev, V. Fursov, V. Ovchinnikov. An adaptive mesh refinement in the finite volume method. Proceedings of Information Technology and Nanotechnology (ITNT-2015) CEUR Workshop Proceedings, vol. 1490, 2015, pp. 234-241.

[7]. Dijkstra E.W. A Discipline of Programming. Prentice-Hall, 1976. 217 p.

[8]. Final drive lubrication OpenFOAM case sources [Электронный ресурс]. https://github.com/j-avdeev/DriveLubrication (4.02.2017).

[9]. H. Rusche, Computational Fluid Dynamics of Dispersed Two-Phase Flows at High Phase Fractions [Электронный ресурс].

http://powerlab.fsb.hr/ped/kturbo/OpenFOAM/docs/HenrikRuschePhD2002.pdf (4.02.2017). 